\title{
Etoposide damages female germ cells in the developing ovary
}

\author{
Agnes Stefansdottir ${ }^{1}$, Zoe C. Johnston ${ }^{1,5}$, Nicola Powles-Glover ${ }^{2}$, Richard A. Anderson ${ }^{3}$, Ian R. Adams ${ }^{4}$ \\ and Norah Spears ${ }^{1 *}$ (iD
}

\begin{abstract}
Background: As with many anti-cancer drugs, the topoisomerase II inhibitor etoposide is considered safe for administration to women in the second and third trimesters of pregnancy, but assessment of effects on the developing fetus have been limited. The purpose of this research was to examine the effect of etoposide on germ cells in the developing ovary. Mouse ovary tissue culture was used as the experimental model, thus allowing us to examine effects of etoposide on all stages of germ cell development in the same way, in vitro.

Results: Fetal ovaries from embryonic day 13.5 CD1 mice or neonatal ovaries from postnatal day 0 CD1 mice were cultured with 50-150 $\mathrm{ng} \mathrm{ml}^{-1}$ or 50-200 $\mathrm{ng} \mathrm{ml}^{-1}$ etoposide respectively, concentrations that are low relative to that in patient serum. When fetal ovaries were treated prior to follicle formation, etoposide resulted in dose-dependent damage, with $150 \mathrm{ng} \mathrm{ml}^{-1}$ inducing a near-complete absence of healthy follicles. In contrast, treatment of neonatal ovaries, after follicle formation, had no effect on follicle numbers and only a minor effect on follicle health, even at $200 \mathrm{ng} \mathrm{ml}^{-1}$. The sensitivity of female germ cells to etoposide coincided with topoisomerase lla expression: in the developing ovary of both mouse and human, topoisomerase lla was expressed in germ cells only prior to follicle formation.
\end{abstract}

Conclusions: Exposure of pre-follicular ovaries, in which topoisomerase lla expression was germ cell-specific, resulted in a near-complete elimination of germ cells prior to follicle formation, with the remaining germ cells going on to form unhealthy follicles by the end of culture. In contrast, exposure to follicle-enclosed oocytes, which no longer expressed topoisomerase lla in the germ cells, had no effect on total follicle numbers or health, the only effect seen specific to transitional follicles. Results indicate the potential for adverse effects on fetal ovarian development if etoposide is administered to pregnant women when germ cells are not yet enclosed within ovarian follicles, a process that starts at approximately 17 weeks gestation and is only complete towards the end of pregnancy.

Keywords: Etoposide, Oogonia, Oocyte, Ovarian follicle, Chemotherapy, Tissue culture, Fetal ovary

\section{Background}

Cancer is diagnosed in approximately one out of every 1000 pregnancies, often requiring consideration of chemotherapy administration to the pregnant woman [1-4]. Chemotherapy administration during the first trimester is now largely avoided, as it is associated with increased risk of congenital malformations and high risk of spontaneous abortion [5]. However, it is now widely considered that chemotherapy treatment during the second and third trimesters of pregnancy is relatively safe for the developing fetus (for example, [6-8]), with

\footnotetext{
* Correspondence: norah.spears@ed.ac.uk

${ }^{1}$ Centre for Integrative Physiology, University of Edinburgh, Edinburgh EH8 9XD, UK

Full list of author information is available at the end of the article
}

several studies showing no congenital malformations in infants born to women receiving chemotherapy at that time $[1,3,5,6]$. Associations have however been made between chemotherapy treatment during pregnancy and increased risk of intrauterine growth restriction, miscarriage, preeclampsia and stillbirth $[4,9]$.

Effects of chemotherapy agents on ovarian function and fertility in girls and young women treated for cancer are well recognised and may result in infertility and premature ovarian insufficiency (POI) $[10,11]$. In contrast, there is a distinct lack of information on the long-term effects of chemotherapy treatment on the future fertility of female fetuses when exposure occurs during the particularly vulnerable window of female germ cell development during fetal life [12], although cyclophosphamide 
exposure in utero results in markedly reduced follicle numbers in neonatal mice [13]. Drug exposure to the developing ovary could have toxic effects on germ and/ or ovarian somatic cells, with the consequences of such effects unlikely to manifest themselves until at least after puberty. Additionally, any genetic damage to germ cells during fetal development could then be passed on to subsequent generations, the 'grand-maternal' effect [14].

Formation of the gonadal ridge begins around week 7 of human gestation, embryonic day 10.5 (E10.5) in the mouse fetus. Shortly after this, proliferating primordial germ cells invade the developing ovary. After a further short proliferative phase, the germ cells initiate meiosis, which subsequently arrests at the diplotene stage of prophase I. Around that time, the germ cells, now termed oocytes, interact with surrounding somatic pregranulosa cells to form primordial follicles (PFs): meiotic arrest and follicle formation start between weeks 17 to 20 of human gestation, although follicle formation can continue until late in pregnancy [15]; in the mouse, oocytes have entered meiotic arrest by the end of gestation, with follicle formation occurring around the time of birth. PF formation, therefore, takes place throughout the second and into the third trimester of human fetal development, compared with peri-natal formation in the mouse (Fig. 1). Once PFs have formed, there is continual 'release' of PFs from that resting follicle pool, follicles then undergoing growth initiation, with the potential to develop through to the preovulatory stage. The number of PFs formed during fetal life is crucial for future fertility, with the size of the PF pool directly related to a female's reproductive lifespan [16].

Etoposide is commonly used in the treatment of ovarian and lung cancers, leukemias and lymphomas. It may be administered during pregnancy $[1,17,18]$, and has been considered safe for the fetus if given during the second or third trimester, with births of healthy babies reported (e.g. [19-21]. However, no data have been reported on possible detrimental effects of etoposide on the reproductive systems of these children, with none having yet reached puberty. Etoposide acts by inhibiting the enzyme type II Topoisomerase (Topo II). Topo II catalyses topological transitions in double-stranded DNA, and thus influences transcription, DNA replication, chromosome condensation and the separation of sister chromatids during mitosis. It creates transient double strand breaks in DNA, relieving the torsional stress created when DNA strands become supercoiled and allowing the passage of the intact DNA segment through the cleaved strand, after which it re-seals the double strand break [22-24]. Etoposide acts by interfering with the ability of Topo II to re-ligate the nick in the DNA

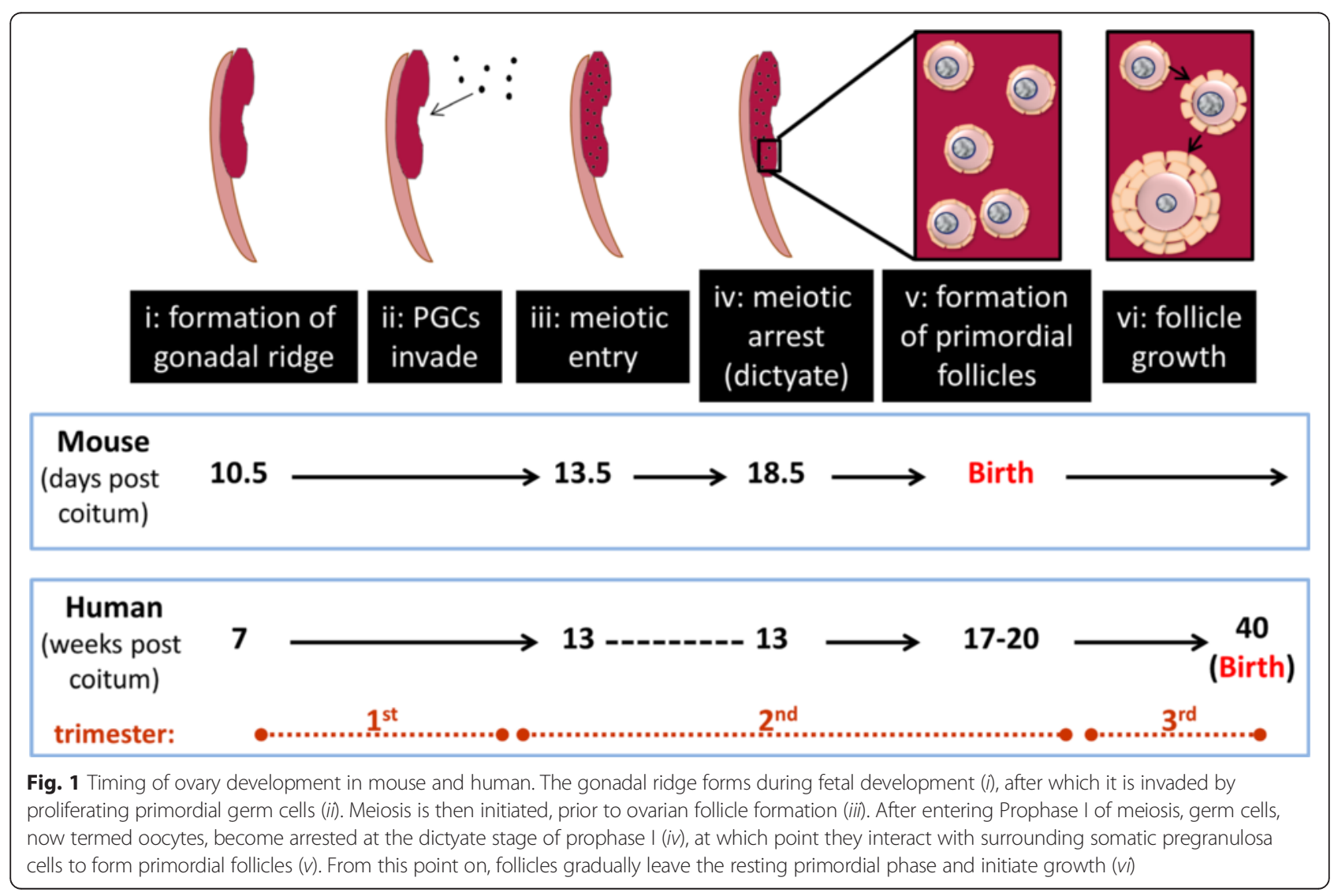


strand, consequently increasing DNA fragmentation and inducing tumour cell death [25-28]. Mammals express two functionally distinct Topo II paralogues: Topo II $\alpha$ and Topo II $\beta$. Topo II $\alpha$ has a widespread role in resolving replication-induced DNA catenanes in proliferating cells, whereas Topo II $\beta$ has a more restricted role, at least in neuronal development, and cannot efficiently provide the essential function of Topo II $\alpha$ in proliferating cells [reviewed in 28]. In the mouse ovary, Topo II $\beta$ is expressed in oocytes at all developmental stages, with a low expression in granulosa cells of PFs and a more pronounced expression in the granulosa cells of growing follicles [29]. Mice with Topo II $\beta$ conditionally deleted from their granulosa cells, contain increased cell DNA damage within the granulosa cells, leading to increased follicle atresia [29]. In male germ cells, Topo II is required during prophase I of meiosis [24, 30, 31], with high levels of chromosomal aberrations present in spermatocytes treated with therapeutic doses of etoposide [32]. These spermatocytes had increased levels of acentric fragments and deletions that are associated with embryonic lethality [32]. In the female, Topo II is required for chromosome separation during oocyte meiotic maturation, but is dispensable for resumption of meiosis [31]. However, its role in early stages of female meiosis, prior to meiotic arrest, remains unclear, as does any effect of etoposide. If a similar effect on meiosis occurring in female germ cells to that which occurs in the male would affect human ovarian development during the second and third trimesters of pregnancy.

We report here on the effects of etoposide on female germ cell development. In the mouse, our experimental model, follicle formation occurs around the time of birth, thus requiring manipulation of both fetal and neonatal ovaries. An initial objective of the work described here was the development of a mouse fetal ovary culture system that traverses both fetal and neonatal stages of germ cell development, thus allowing us to examine effects of etoposide on all stages of germ cell development in a consistent manner, in vitro. This novel fetal ovary culture technique supports survival of pre-meiotic germ cells, progression through prophase I of meiosis up to meiotic arrest, followed by follicle formation and subsequent growth initiation, and has been used here alongside an established neonatal ovary culture system in which oocytes have already entered meiotic arrest prior to culture [33,34]. In vitro models are a growing area in reproductive toxicology research, allowing pragmatic and mechanistic studies of action of chemicals. The rodent ovary is an excellent model for in vitro studies, partly due to its small size, short time-course, high material availability, and similarities in many key developmental and functional aspects with the human ovary. A second aim was to determine the expression pattern of mammalian Topo II $\alpha$ in the ovary, which has not yet been reported: it has been examined here, in mouse and human. The main goal of this work was to use ovarian tissue culture methods to investigate the effect of etoposide on germ cells prior to and following follicle formation. Our results show that germ cells are particularly sensitive to etoposide damage prior to follicle formation, the only stage at which both Topo II $\alpha$ and TopoII $\beta$ are expressed in the oocyte in the developing mouse and human ovary.

\section{Results}

Tissue culture supports physiological development of fetal mouse ovaries

A culture technique to support development of fetal mouse ovaries from E13.5 was developed, to allow effects of etoposide to be examined both before and after follicle formation in a consistent manner, in vitro, with neonatal mouse ovary culture already an established method. Over the 12 days of culture, germ cells progressed through prophase I of meiosis, followed by formation of PFs, with some follicles subsequently initiating follicle growth to the transitional and primary follicle stage (Fig. 2Ai,ii). Cultured follicles were morphologically healthy, similar to that observed in uncultured postnatal day 4 (P4) in vivo ovaries (Fig. 2Aiii). Although there was a significant reduction in follicle numbers within cultured ovaries compared to in vivo $\mathrm{P} 4$ ovaries (Fig. 2Bi; $p<0.01, n=5$, from 3 independent cultures), health and follicle developmental stage were both comparable to that found in vivo (Fig. 2Bii,iii). Progression of cultured oocytes through prophase I of meiosis to diplotene was analysed through visualisation of Sycp3. Sycp3 is a component of the axial/lateral element of the synaptonemal complex (SC) that assembles during meiotic prophase I $[35,36]$. In the female mouse embryo, germ cells enter meiosis at E13.5 and progress through prophase I to diplotene over the next 6-7 days [37]. Images here show that meiosis progressed in vitro as in vivo: oocytes progressed through leptotene/zygotene, pachytene, and diplotene, as assessed by SC assembly and disassembly (Fig. 3Ai-iii). In vitro oocytes were observed in all stages of prophase I, with $57.1 \%$ still leptotene/zygotene and $42.3 \%$ having reached pachytene by Day 2 of culture. By Day 4 of culture, the vast majority (99.2 \%) had reached pachytene, and by Day 6 of culture, the majority $(82.5 \%)$ of oocytes had progressed through to the diplotene stage of prophase I (Fig. 3B, upper panel): by Day 6 of culture, no leptene/zygotene oocytes remained, as would be expected at the equivalent E19.5 point in vivo [37]. Together, these results validate the use of this fetal ovary culture system for investigations into meiotic progression and follicle formation. 


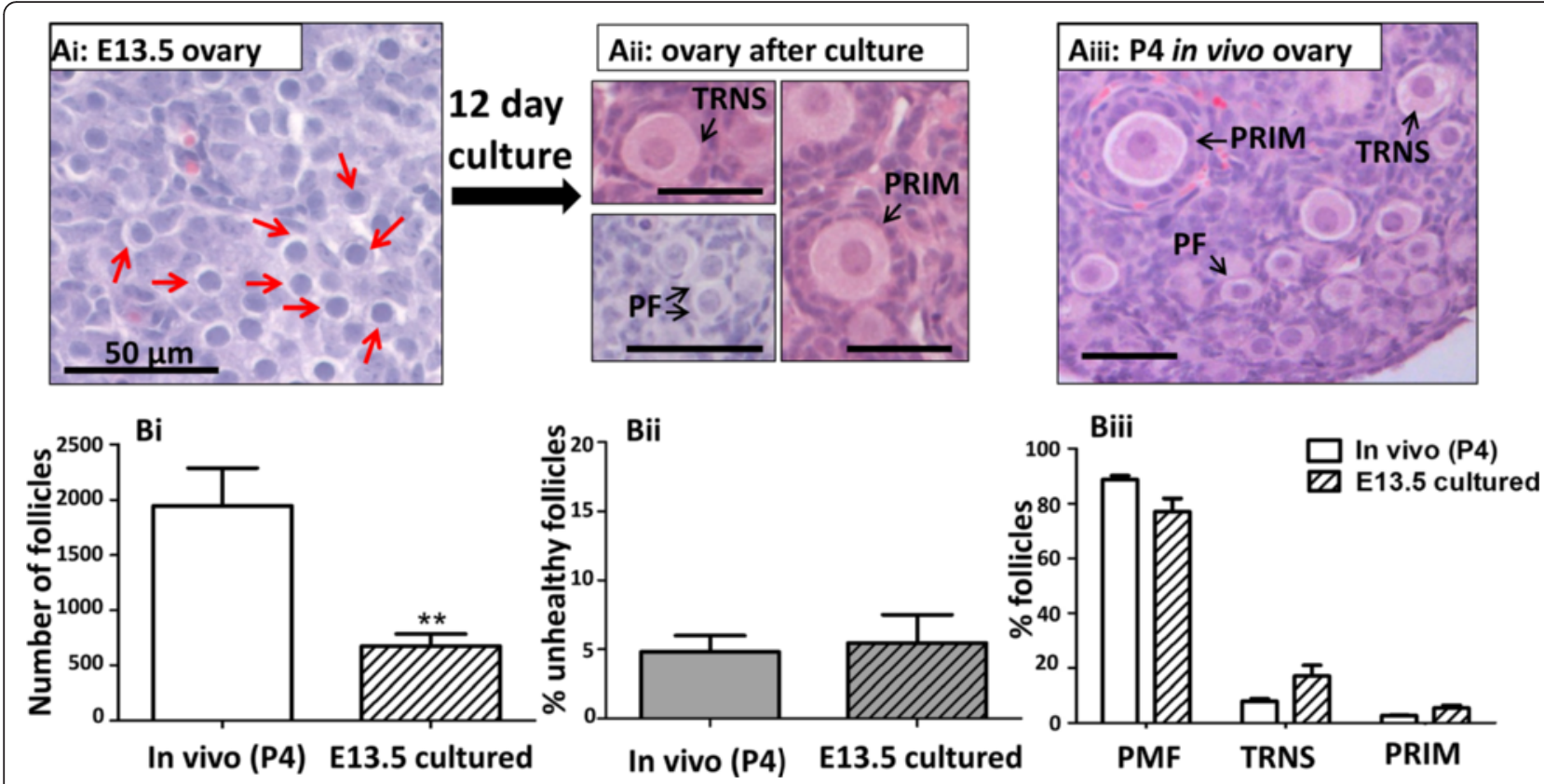

Fig. 2 Fetal ovary culture supports follicle formation and further development to the primary stage, as occurs in vivo. Representative histological sections of cultured E13.5 mouse ovary prior to (Ai), and after (Aii) 12 days of culture, compared with in vivo P4 mouse ovary (Aiii). At the end of culture, healthy primordial, transitional and primary follicles formed within cultured ovaries (Aii), morphologically highly similar to those found in uncultured ovaries of equivalently aged mice (P4) (Aiii). Despite a smaller number of follicles in cultured ovaries (Bi), very few follicles were unhealthy, with no difference compared to the percentage of unhealthy follicles found in in vivo ovaries (Bii), and with follicles present at developmental stages in ratios comparable to those present in P4 in vivo ovaries (Biii). Scale bars: $50 \mu \mathrm{m}$. Histogram bars denote mean \pm SEM; $n=5$ for all groups. Stars denote significant differences relative to control (** $p<0.01)$

\section{Germ cells are more vulnerable to etoposide exposure prior to follicle formation}

We first tested whether etoposide might be impairing the ability of fetal oocytes to progress through meiotic prophase. Fetal mouse ovaries were immunostained for Sycp3 after culture in control medium, or in the presence of etoposide (150 ng ml $\mathrm{m}^{-1}$ ) for 2, 4 or 6 days to assess progression through early prophase I. There was a difference between etoposide-treated and control oocytes at Day 2 of culture $(p<0.01)$, but the effect was no longer observed by Days 4 or 6 of culture (Fig. 3B; $p=$ 0.4 at Days 4 and 6). The effect at Day 2 could be due to an initial 'acceleration' in meiosis in germ cells exposed to etoposide, or because the germ cells are more sensitive to etoposide at mitotic and/or pre-leptotene stages: increased sensitivity is perhaps more likely given the reduction in follicle number after etoposide exposure (see results below). Overall, results show that female germ cells are able to progress through meiosis to the diplotene stage of prophase I in the presence of etoposide.

E13.5 fetal mouse ovaries were then cultured for twelve days either in control medium throughout (Days $0-12)$, or exposed to a range of etoposide doses $(50,100$ or $150 \mathrm{ng} \mathrm{m}^{-1}$ ) for the first six days of culture (Days 0$6)$, followed by a further six days in control medium (Days 6-12): Day 7 of culture, when follicles have begun to form in the cultured fetal mouse ovaries, was considered as equivalent to the day of birth in vivo. Etoposide exposure occurred, therefore, prior to follicle formation, spanning entry into meiotic prophase and progression through to diplotene stage.

Over the twelve days of culture, oocytes entered meiotic prophase and formed follicles, with some follicles then initiating growth to the primary stage. At the end of culture, histological sections of cultured ovaries were examined (Fig 4Ai-iii), follicles counted and assessed for health. Etoposide had a markedly detrimental effect on total follicle numbers, with a dose-dependent loss of follicles of $72.5 \%$ and $89.7 \%$ at the medium and high doses respectively (Fig. $4 \mathrm{Bi}, p<0.01$ at $100 \mathrm{ng} \mathrm{ml}^{-1}, p<0.001$ at $150 \mathrm{ng} \mathrm{ml}$ ${ }^{-1} ; n=6,2$ independent cultures). The observed follicle reduction was due to a loss in PF and transitional follicles within these ovaries (Fig. 5Ai, $p<0.01 ; n=6$ ). The loss was particularly marked for PFs, which constitute over $75 \%$ of the follicles in control ovaries, with numbers reduced to $3.7 \%$ of controls after exposure to $150 \mathrm{ng} \mathrm{ml}^{-1}$, compared to $25 \%$ of transitional follicles remaining. The percentage of follicles assessed as unhealthy also increased in a dose dependent manner with increasing etoposide dose, reaching significance at the highest dose of etoposide (Fig. $4 \mathrm{Ci}, p<0.05 ; n=6$ ). Again, when each follicle stage was examined, this was seen to be due to a significant 


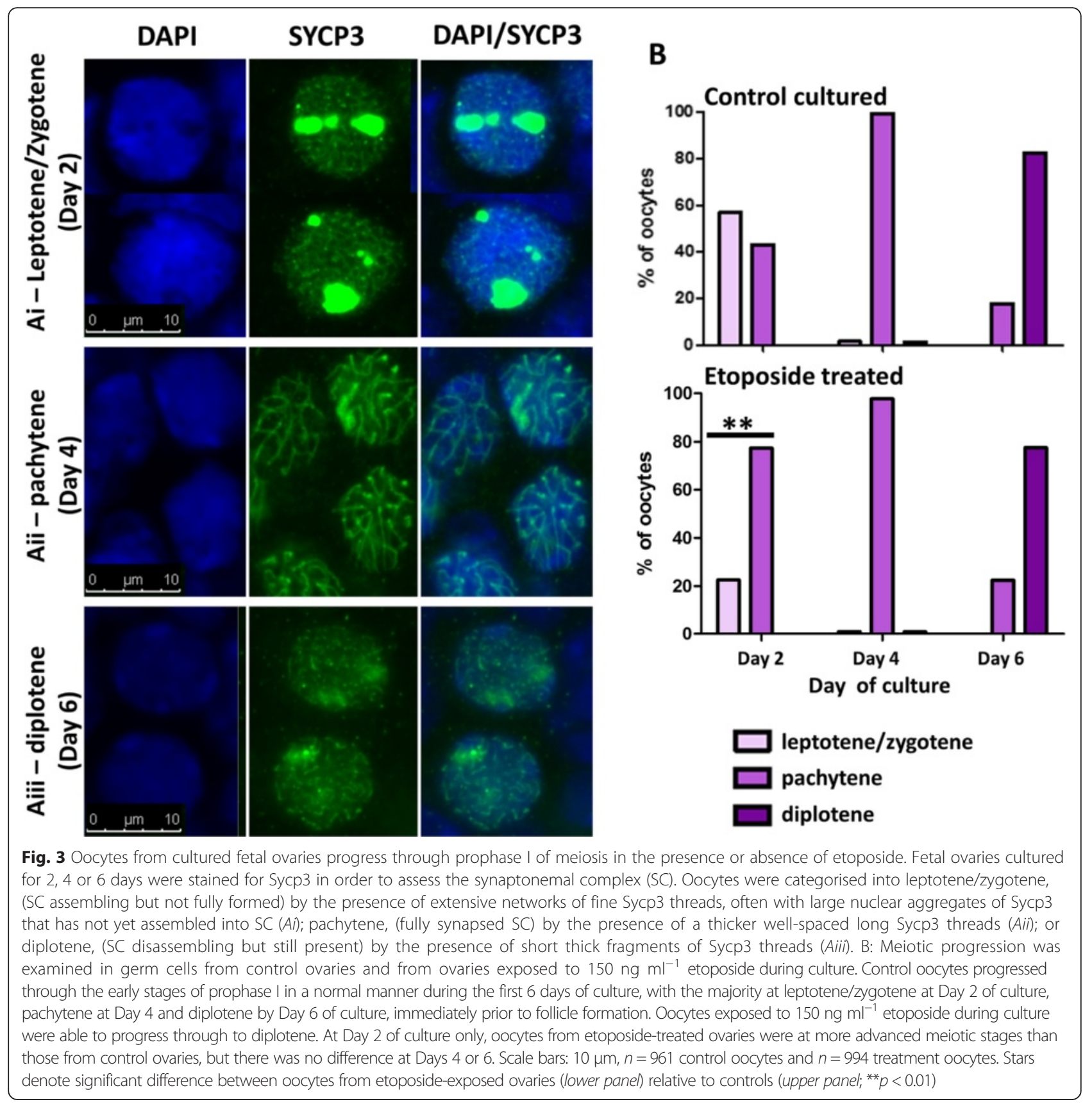

increase in the percentage of $\mathrm{PF}$ and transitional follicles assessed as unhealthy (Fig. $5 \mathrm{Bi}, p<0.05 ; n=6$ ). Ovaries were then examined histologically at day 6 of culture, considered as equivalent to the last day of gestation, a time point at which germ cells are beginning to form follicles (Fig. 6Ai,ii). Ovaries cultured in the presence of the highest dose of etoposide (150 $\mathrm{ng} \mathrm{ml}^{-1}$ ) had markedly and significantly fewer germ cells than controls, indicating that the reduced number of follicles observed at the end of culture (Figs. 4Bi and 5Ai) was due to germ cell loss prior to follicle formation (Fig. 6B, $p<0.0001, n=5$ for controls, $n=6$ for treatment group).
To investigate the effects of etoposide on folliculogenesis after germ cells are already enclosed in follicles, neonatal mouse ovaries were cultured for six days in control medium or exposed to etoposide (50, 100, 150 or $200 \mathrm{ng} \mathrm{ml}^{-1}$ ) for the duration of culture. Over the six days of culture, some PFs initiated growth to the transitional or primary stage, with a few reaching the secondary stage. In contrast to the fetal ovary culture experiments, when oocytes were exposed to etoposide after follicle formation, no effect was seen on total follicle number (Fig. 4Bii, $p=0.092 ; n=6,4$ independent cultures), or the percentage of unhealthy follicles 


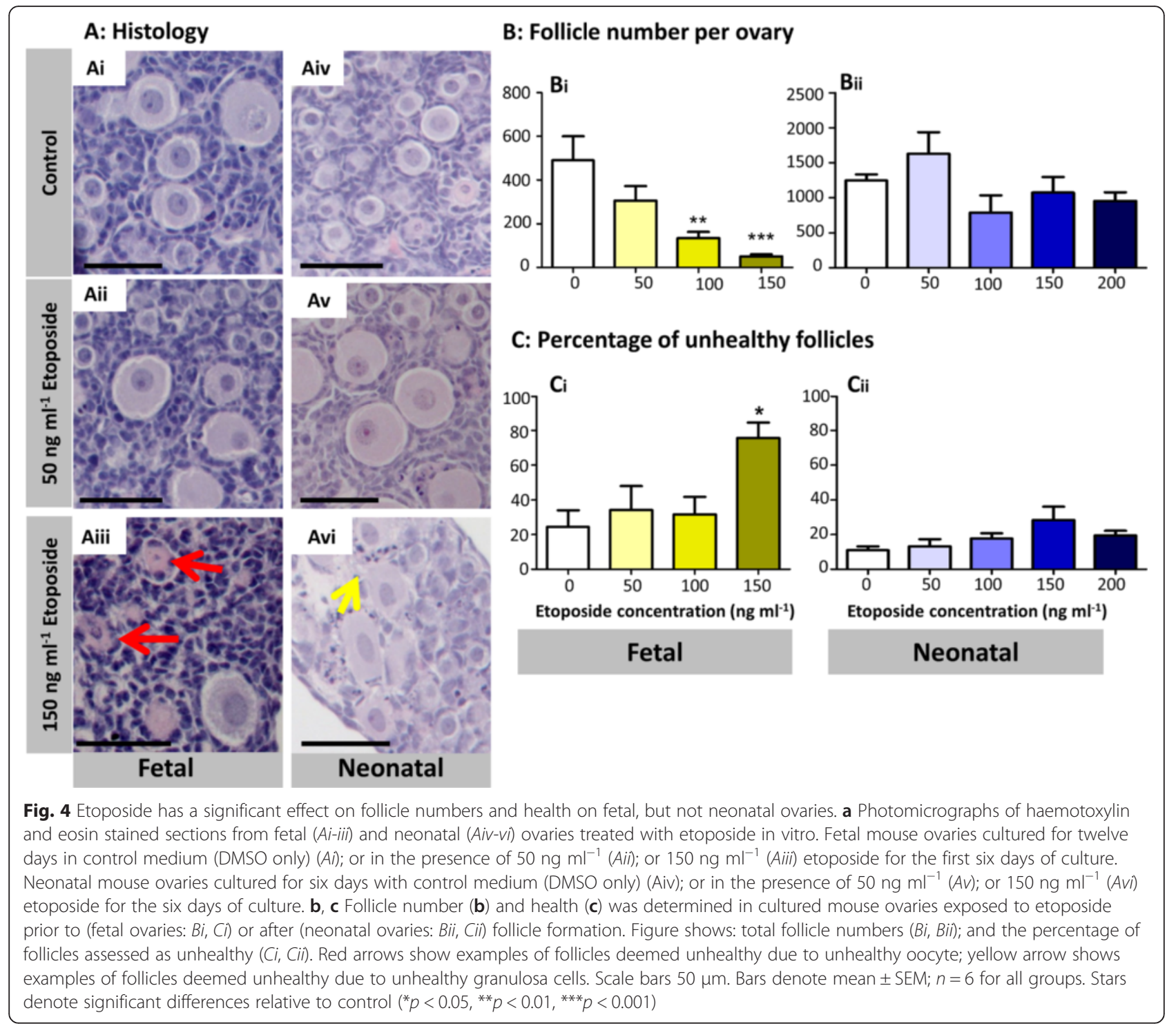

(Fig. 4Cii, $p=0.082$ ), despite exposing neonatal ovaries to a higher concentration of etoposide $\left(200 \mathrm{ng} \mathrm{ml}^{-1}\right.$, compared with the highest dose of $150 \mathrm{ng} \mathrm{ml}^{-1}$ for fetal ovary cultures). When each follicle stage was examined individually, the only effect seen was at the transitional stage, which accounts for $15 \%$ of follicles in control ovaries. Here, etoposide significantly decreased transitional follicle numbers at 100, 150 and $200 \mathrm{ng} \mathrm{ml}^{-1}$ doses (Fig. 5Aii, $p<0.05, p<0.01$ and $p<0.05$ respectively; $n=6$ ) with a corresponding increase in the percentage of transitional follicles assessed as unhealthy only at the highest dose (Fig. 5Bii, $p<0.01 ; n=6$ ). There was no significant effect on the number or health of PFs $(p=0.101, p=0.173$ respectively) or primary follicles $(p$ $=0.604, p=0.129$ respectively).

Overall, results show a marked effect of etoposide on follicle number only when ovaries are exposed prior to follicle formation (fetal ovary culture), with significantly fewer follicles remaining even when exposed to doses as low as $100 \mathrm{ng} \mathrm{ml}^{-1}$. In contrast, exposure of ovaries to etoposide only after follicle formation (neonatal ovary culture), has no effect on overall follicle number or health even up to the highest dose of $200 \mathrm{ng} \mathrm{ml}^{-1}$, with the only significant effect found specifically on transitional stage follicles.

\section{Etoposide affects different follicular cell types depending} on the time of exposure

Figure 4 showed the appearance of unhealthy follicles with unhealthy oocytes in cultured fetal ovaries, exposed to etoposide only prior to follicle formation (Fig. 4Aiii: red arrows), in contrast to the unhealthy follicles with unhealthy granulosa cells in cultured neonatal ovaries, exposed to high concentrations of 


\section{A: Number of follicles}
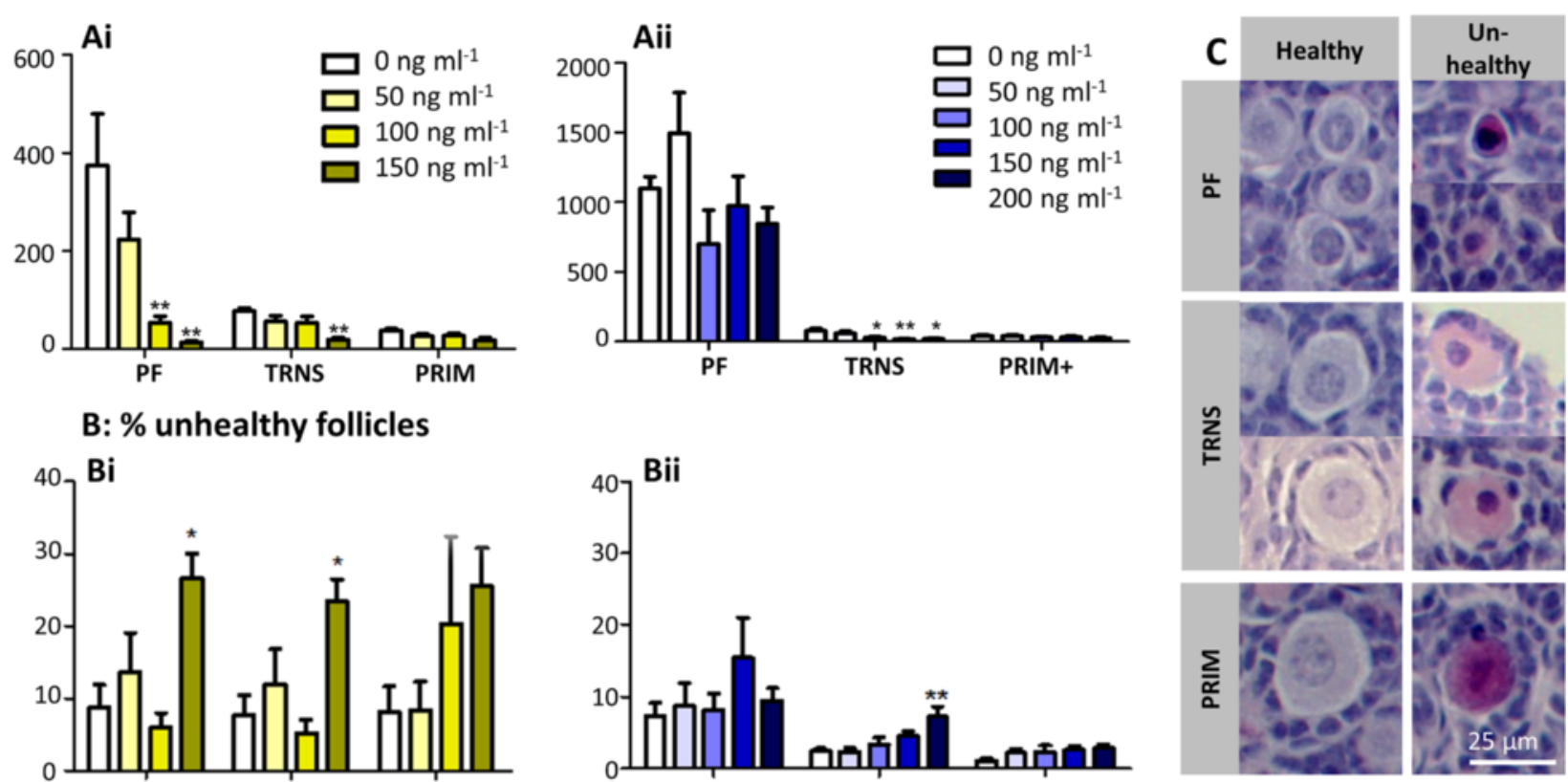

B: \% unhealthy follicles
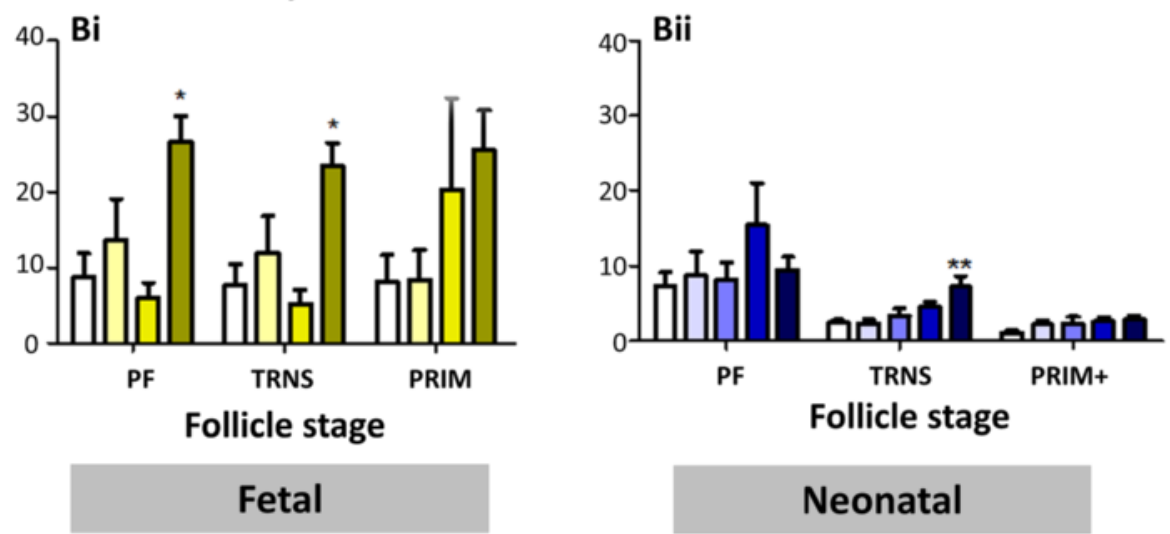

Neonatal

Fig. 5 Effect of etoposide on different stages of follicle development. Number and health of primordial (PF), transitional (TRNS) and primary (PRIM) follicles was determined in cultured mouse ovaries exposed to etoposide prior to (fetal ovaries: Ai, Bi); or after (neonatal ovaries: Aii, Bii) follicle formation. Figure shows: follicle distribution (Ai, Aii); and the percentage of follicles assessed as unhealthy for each follicle stage (Bi, Bii). c Photomicrographs of haemotoxylin and eosin stained cultured fetal and neonatal ovary sections, comparing healthy and unhealthy primordial, transitional and primary follicles. Bars denote mean $\pm \mathrm{SEM} ; n=6$ for all groups. Stars denote significant differences relative to control $\left(^{*} p<0.05\right.$, $\left.{ }^{* *} p<0.01,{ }^{* * *} p<0.001\right)$

etoposide only after follicle formation (Fig 4Avi: yellow arrows). In order to examine this in more detail, all histological sections were assessed further, with each unhealthy follicle classified as having: (i) an unhealthy oocyte only; (ii) unhealthy granulosa cells only; or (iii) unhealthy oocyte and granulosa cells. Exposure of fetal ovaries to etoposide resulted in a significant increase in the proportion of follicles with morphologically unhealthy oocytes (Fig. 7Ai, $p<0.05$ ), with no effect observed either on the proportion of follicles with unhealthy granulosa cells only or unhealthy oocyte and granulosa cells (Fig. 7Aii,iii, $p=$ 0.429 and 0.470 respectively). In contrast, neonatal cultured ovaries exposed to etoposide only after follicle formation, exhibited a significant increase in the proportion of follicles assessed as unhealthy due to unhealthy granulosa cells, or where both the oocyte and granulosa cells were unhealthy (Fig. 7Bii, Biii, $p<$ $0.05 ; n=6$ ), with no significant effect on the proportion of follicles assessed as unhealthy due to an unhealthy oocyte (Fig. 7Bi, $p=0.069 ; n=6$ ).
Topo lla is expressed in the female germ cell only prior to follicle formation

Lastly, we sought to investigate why etoposide was having more pronounced effects on oocyte rather than granulosa health in fetal ovaries, but less predominantly affecting the somatic granulosa cells rather than the oocyte in neonatal ovaries. Etoposide functions by inhibiting Topo II, preventing it from re-ligating the doublestranded DNA breaks that Topo II introduces [22, 24, 25]. TopoII $\beta$ has been previously reported to be expressed in oocytes at all developmental stages, and is also expressed in granulosa cells of PF and growing follicles [29]. TopoII $\alpha$ plays a more widespread role in resolving replication-induced topological structures than TopoII $\beta$ [revieved in Refs 24 and 28] and could also be contributing to etoposide sensitivity in the developing ovary. Immunohistochemistry was used to assess Topo II $\alpha$ expression within the developing mouse ovary, both in vivo from E13.5 through to P6 and in vitro throughout the course of the fetal ovary culture. It was also investigated in a second trimester fetal human ovary, a 

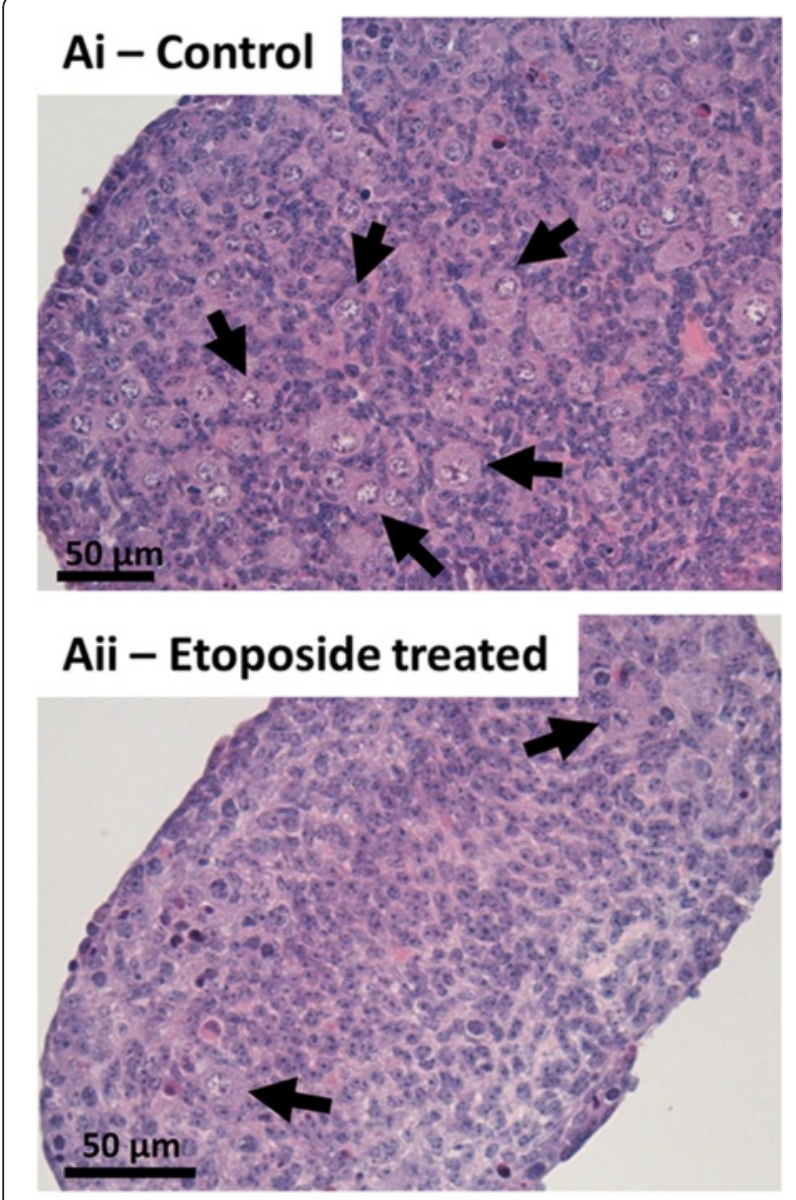

\section{B}

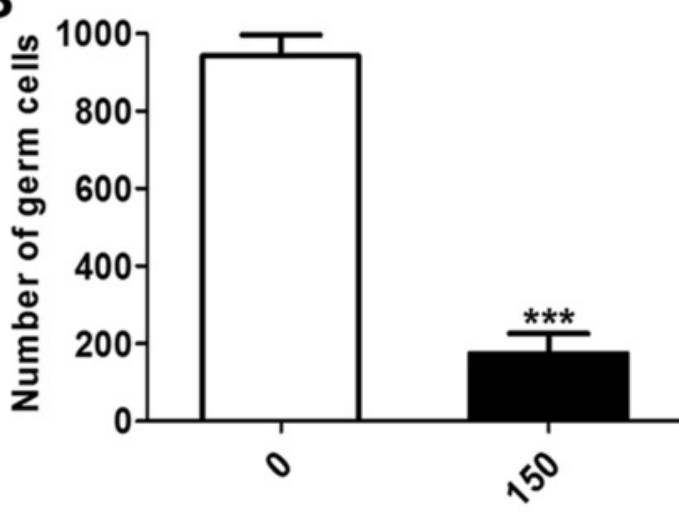

Etoposide concentration $\left(\mathrm{ng} \mathrm{ml}^{-1}\right)$

Fig. 6 Germ cells show impaired capability of forming follicles in the presence of etoposide. A: Photomicrographs of haemotoxylin and eosin stained E13.5 CD1 ovaries cultured for 6 days either in control medium (Ai) or in medium supplemented with the highest dose of etoposide (150 $\mathrm{ng} \mathrm{ml}^{-1}$; Aii). By day 6 of culture, there were significantly fewer germ cells remaining in etoposide-treated ovaries than in controls (b). Arrows denote germ cells within the ovary. Scale bars: both $50 \mu \mathrm{m}$. Bars denote mean \pm SEM, $n=5$ for controls, $n=6$ for treatment group. Stars denote significant differences relative to control $\left({ }^{* *} p<0.0001\right)$ developmental stage at which the ovary contains female germ cells both prior to and subsequent to follicle formation. In the mouse, both in vivo and in vitro, Topo II $\alpha$ expression changed from a germ cell-only location prior to follicle formation, to a somatic cell-only location after follicle formation, primarily in granulosa but also expressed in some stromal cells (Fig. 8a, b). Similarly, in the developing human ovary, Topo II $\alpha$ was expressed in germ cells only prior to follicle formation, although here Topo II $\alpha$ was no longer expressed after follicle formation (Fig. 8c). The damaging effect of etoposide on ovarian germ cells (Figs. 4, 5 and 6) is, therefore, pronounced only when etoposide exposure is coincident with Topo II $\alpha$ germ cell-specific expression. Thus the developmental regulation of Topo II $\alpha$ expression could be one of the factors contributing to the more pronounced effect of etoposide on fetal ovaries, when germ cells express Topo II $\alpha$.

\section{Discussion}

The Topo II inhibitor etoposide has been administered to women during pregnancy, with healthy babies born, although there are no data on the side-effects of etoposide on the reproductive system of these children, as none have yet reached puberty. Our results, using in vitro systems to assess the effects of etoposide, show that exposure of pre-follicular ovaries to etoposide results in a near-complete elimination of healthy follicles by the end of culture. This observed lack of follicles is a direct result of etoposide-treated pre-follicular germ cells failing to survive, with only a small proportion capable of forming follicles. Etoposide was used in concentrations considerably lower than those measured in the serum of patients, concentrations of $50-150 \mathrm{ng} \mathrm{ml}^{-1}$ being used, compared with 5-60 $\mu \mathrm{g} \mathrm{ml}^{-1}$ in patient serum [38]. In contrast, exposure to oocytes once they were enclosed in follicles had no effect on total follicle numbers or health, the only effect seen on transitional follicles, and only when ovaries were exposed to a higher dose of $200 \mathrm{ng} \mathrm{ml}^{-1}$. Thus once follicles have formed, the oocytes are less susceptible to etoposide-induced damage. One possible explanation for this change is that Topo II $\alpha$ was found to be expressed in female germ cells only prior to follicle formation, in both mouse and human. Despite the obvious differences between the mouse ovary cultures described here and the real-life situation of exposure to a human fetus, the results obtained do indicate a cause for concern, especially since etoposide has already been prescribed to pregnant women. Setting aside inter-species differences, it is possible that since etoposide targets mouse germ cells in our culture system, that a similar effect might be observed in a human fetal ovary exposed in vivo. This is especially true if etoposide inhibits Topo II $\alpha$ in the human ovary, the 


\section{A: Fetal ovary culture}
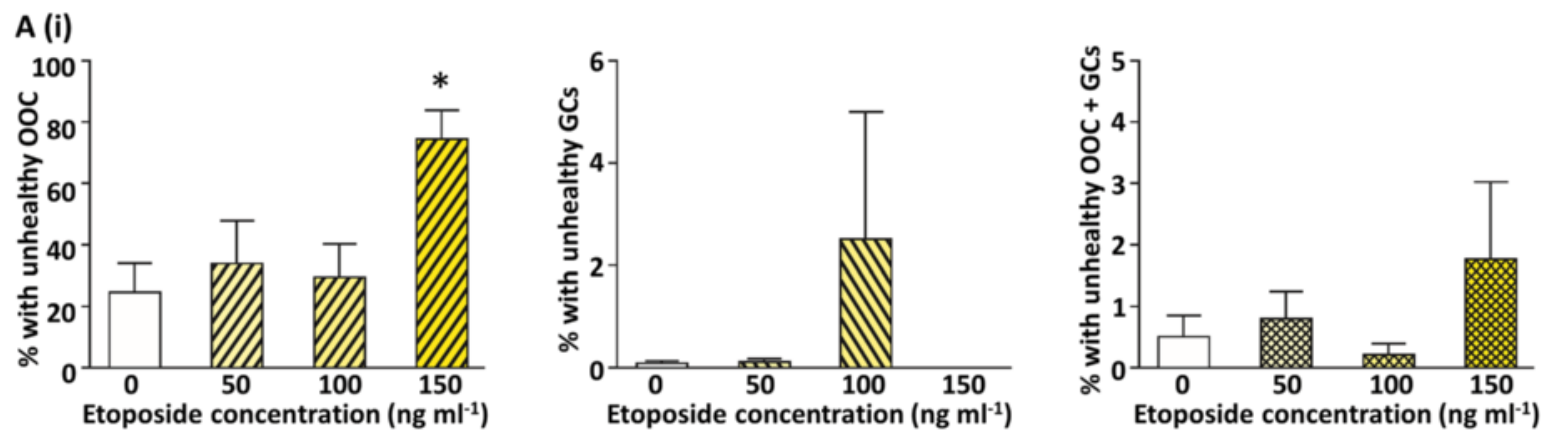

\section{B: Neonatal ovary culture}
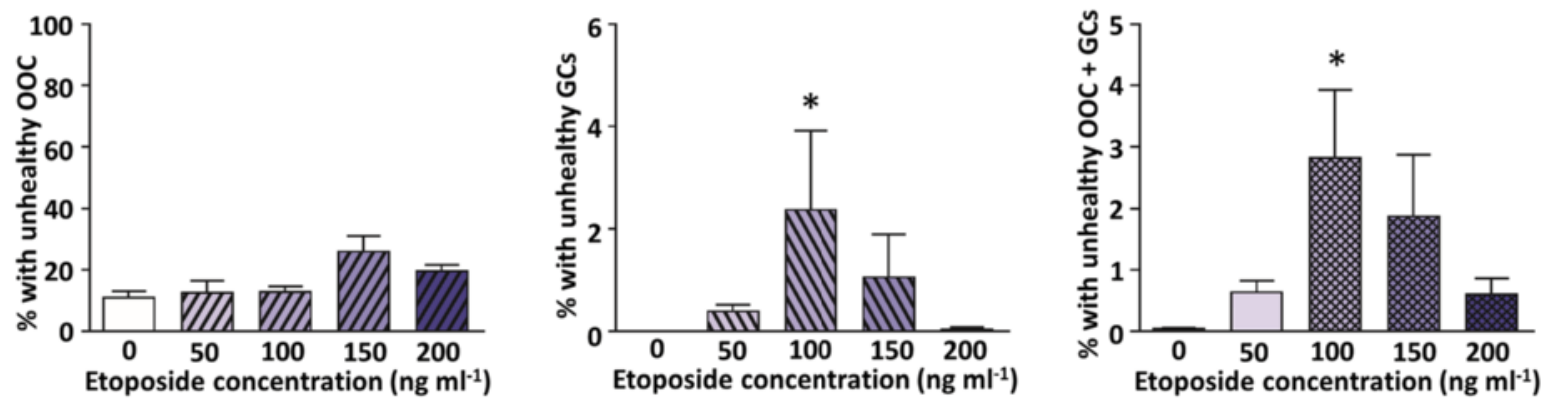

\section{ZUUnhealthy oocyte only}

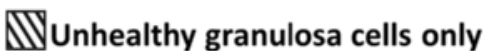

Unhealthy oocyte and granulosa cells

Fig. 7 Etoposide primarily targets oocytes prior to follicle formation and granulosa cells after follicle formation. Follicles were categorised as unhealthy due to: unhealthy oocyte (OOC) only (i); unhealthy granulosa cells (GCs) only (ii); or unhealthy oocyte and granulosa cells (OOC + GCs) (iii), in fetal (a) or neonatal (b) mouse ovaries exposed to etoposide. Bars denote mean \pm SEM; $n=6$ for all groups. Stars denote significant differences relative to control ( ${ }^{*} p<0.05$ )

expression pattern of which is the same in both the human and mouse ovary. Reassuringly, results here showed little evidence of an effect of etoposide on the ability of oocytes to progress through early prophase I of meiosis. Etoposide-treated oocytes were able to reach the diplotene stages of meiosis by the end of culture, although there was an effect of etoposide treatment at Day 2 of culture only, at which point a higher proportion of etoposide-treated oocytes had progressed through leptotene and zygotene to reach the pachytene stage, perhaps indicating that the female germ cells are sensitive to etoposide at mitotic and/or pre-leptotene stages. However, the ability of cultured oocytes in this study to progress through early meiosis without delay does not rule out the possibility that they may have developed DNA damageinduced mutations or chromosomal re-arrangements following etoposide treatment. There may therefore be underlying genetic or chromosomal abnormalities present within these oocytes, which would only become evident much later in oogenesis during meiotic chromosome segregation, or even in a resulting embryo.

Etoposide has previously been shown to directly inhibit the action of Topo II [25-28, 39], and our results here are consistent with this, in particular indicating that the effect of etoposide is most noticeable in cells expressing both Topo II $\alpha$ and $\beta$. When etoposide was administered prior to follicle formation, during the timeframe that both Topo II $\alpha$ and $\beta$ are expressed in female germ cells, follicle loss along with a rise in the number of follicles with unhealthy oocytes was observed. In contrast, when etoposide was administered after follicle formation, when Topo II $\alpha$ is no longer expressed in germ cells, although expression of Topo II $\beta$ continues [29], only subtle germ cell effects were found. Our finding that the oocyte's sensitivity to etoposide correlates with developmental stages when both Topo II $\alpha$ and $\beta$ are expressed, rather than expression of Topo II $\beta$ alone, is consistent with findings in proliferating cell types that Topo II $\alpha$ provides essential functions that cannot always be efficiently complemented by Topo II $\beta$ [reviewed in 28 ]. On the other hand, after follicle formation, when Topo II $\alpha$ and $\beta$ are both expressed in granulosa cells, there is a corresponding increase in the proportion of follicles with unhealthy granulosa cells. The sensitivity of fetal oocytes and post-natal granulosa cells to etoposide presumably reflects Topo II activity in these cells, but 

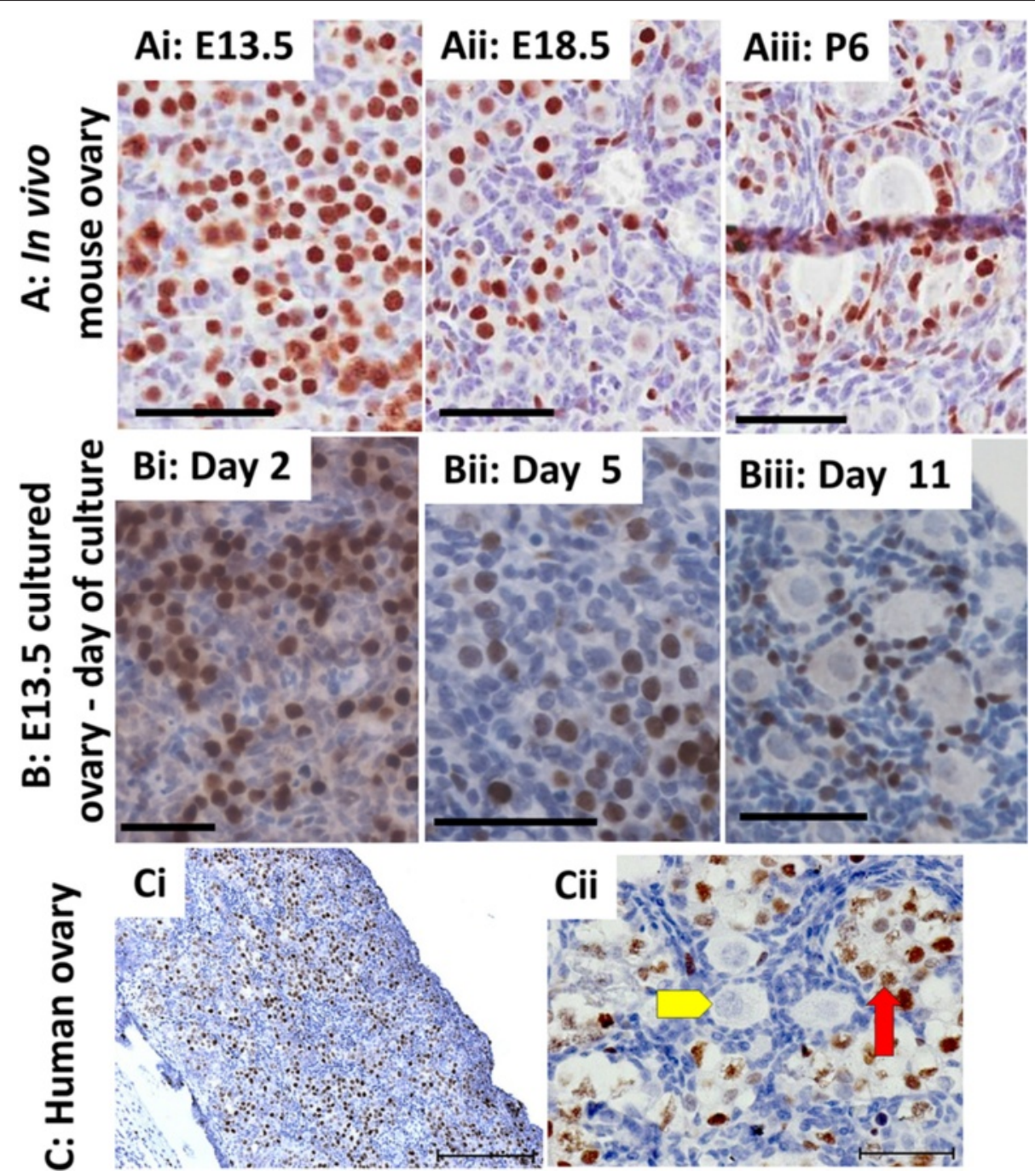

Fig. 8 Topo lla is expressed in the germ cell only prior to follicle formation in the mouse and human ovary. a, b Topo lla was localised within the germ cells during pre-natal mouse ovary development (Ai,ii), and during the equivalent time in vitro, for the first 5 days of culture (Bi,ii). After follicles formed, Topo lla expression was no longer found within germ cells, instead localised to surrounding somatic cells, both in vivo (Aiii) and in vitro (Biii). c Topo lla expression was localised to germ cells not yet enclosed in follicles, in ovaries from week 19 human embryos (Ci, Cii). Cii: red arrow denotes example of Topo lla expression in germ cell prior to follicle formation, while yellow arrowhead denotes example of absence of Topo lla expression in germ cell enclosed within ovarian follicle. Scale bars: all 50 um, except Ci where $200 \mu \mathrm{m}$

further work will be required to determine whether the effects of etoposide on oocytes and granulosa cells are caused by DNA double strand breaks generated by etoposide-mediated inhibition of Topo II $[25,26,28]$, or by defects in transcription, chromosome structure or chromosome segregation which are all influenced by Topo II activity [24].

In vitro organ and cell culture has become a widely used tool within the field of reproductive toxicology, providing a pragmatic and mechanistic method to study the actions of reproductive toxicants. There are, however, limitations to this method, in that it is difficult to account for any indirect action of a compound that can modulate hormone-signalling pathways. Furthermore, in vitro methods are unable to take into consideration metabolism of the compound, with an effect observed in vivo not necessarily being replicated in vitro. Despite this, in vitro systems have become an invaluable preliminary screening method to discover and investigate potentially harmful compounds on the reproductive system. In vitro systems also have the added advantage that they can reduce the number of animals required for in vivo studies. Work here uses a novel fetal ovary culture system. The method supports female germ cell entry into meiosis, nest breakdown, entry into meiotic arrest, follicle formation and initiation of follicle growth, and allows formation of healthy follicles in ratios comparable to that observed in the neonatal mouse ovary in 
vivo. Relatively few previous culture systems have been attempted that cover progression into prophase I of meiosis [40-46], and these have not supported subsequent development to the physiological end point of ovarian follicles without the use of invasive techniques [47]. As such, although we have not developed this novel culture system to support follicle growth beyond the primary follicle stage, it could provide an important tool for investigations into early ovary development, including toxicological studies.

\section{Conclusions}

Overall, our results show that early stage female germ cells, prior to follicle formation, are particularly susceptible to levels of etoposide that are low relative to patient serum levels. This effect of etoposide was shown to coincide with a change in Topo II $\alpha$ expression, with Topo II $\alpha$ expressed only within female germ cells prior to follicle formation, in the developing ovary of both mouse and human. Our findings indicate the potential for adverse effects on fetal ovarian development when etoposide is used as a chemotherapeutic agent in pregnant mothers during the second or third trimesters, at which point pre-follicular female germ cells are sensitive to the detrimental effects of this compound: effects at this stage of ovary development may well not become apparent until many years later.

\section{Methods}

\section{Animals}

All experiments were approved by the University of Edinburgh's Local Ethical Review Committee and carried out in accordance with UK Home Office regulations under the ASPA 1986 act. Wild-type CD-1 mice were maintained and bred in an environmentally-controlled room on a 14-h light:10-h dark photoperiod. To obtain fetuses for fetal ovary culture experiments, mouse breeding harems were set up and females checked for the presence of a copulation plug, then designated as E0.5.

\section{Ovary culture}

\section{Fetal ovary culture}

Pregnant timed-mated females were obtained at E13.5 and culled by cervical dislocation. Genital ridges containing the developing fetal ovaries with mesonephros attached were dissected from female embryos and placed in $1 \mathrm{x}$ PBS at $4{ }^{\circ} \mathrm{C}$ (day of dissection: Day 0). Ovarymesonephros complexes were cultured for a total of 12 days on a $2 \%$ agar block (Sigma Aldrich Ltd, Dorset $\mathrm{UK})$ in a $33 \mathrm{~mm}$ petri dish, incubated at $37{ }^{\circ} \mathrm{C}, 5 \% \mathrm{CO}_{2}$ : see Additional file 1 for further detail. During the first three days of culture (Days 0-3), culture medium contained Dulbecco's Minimal Essential medium (Life Technologies, Paisley, UK) supplemented with $10 \%$ fetal calf serum (Thermo Fisher, Loughborough UK), 2 mM Lglutamine (Invitrogen), $10 \mu \mathrm{M} \beta$-mercaptoethanol (Life Technologies), $1 \%$ sodium pyruvate (Sigma Aldrich), $1 \%$ penicillin/streptomycin (Invitrogen, Paisley UK) and $1 \%$ amphotericin B (Sigma Aldrich). For the subsequent 9 days of culture (Days 3-12), culture medium was replaced with a simpler culture medium composed of $\alpha$ MEM medium (Invitrogen) supplemented solely with $3 \mathrm{mg} \mathrm{m} \mathrm{m}^{-1}$ bovine serum albumin (Sigma Aldrich). Medium was topped up with approximately $200 \mu \mathrm{l}$ of fresh medium daily, and replaced totally with fresh medium every $72 \mathrm{~h}$.

The effect of etoposide on ovary development was assessed by adding varying doses of etoposide (Sigma Aldrich) to the medium for the first 6 days of culture (Days 0-6). Etoposide was dissolved in DMSO (Sigma Aldrich), therefore DMSO was also added to control medium, with all media containing 0.1 \% DMSO. Etoposide was added to produce final concentrations of 50 , 100 or $150 \mathrm{ng} \mathrm{ml}^{-1}$ (highest concentration of etoposide used was determined from preliminary experiments to find the lowest dose that resulted in the death of the majority of follicles: data not shown). Ovaries were then moved to drug-free culture medium for a further six days (Days 6-12). At the end of culture (Day 12), ovaries were fixed and processed for immunohistochemical or histological analysis. All treatments were $n=6$, based on initial unpublished work examining ovary development over the time-course of this culture method.

\section{Neonatal ovary culture}

P0 female mice were culled by decapitation and ovaries dissected out into Leibovitz L-15 dissection medium (Invitrogen) supplemented with $3 \mathrm{mg} \mathrm{ml}^{-1}$ bovine serum albumin (Sigma Aldrich); day of dissection: Day 0. Ovaries were cultured for 6 days in a 24-well culture plate (Greiner Bio-one, Stonehouse UK), on Whatman nucleopore polycarbonate membranes (Camlab Ltd, Cambridge UK, $13 \mathrm{~mm}, 8.0 \mu \mathrm{m}$ ) floating on $\alpha$-MEM medium (Invitrogen) supplemented with $3 \mathrm{mg} \mathrm{ml}^{-1}$ bovine serum albumin, incubated at $37{ }^{\circ} \mathrm{C}, 5 \% \mathrm{CO}_{2}$. Culture medium was supplemented with varying doses of etoposide to produce final concentrations of 50, 100, 150 or $200 \mathrm{ng} \mathrm{ml}^{-1}$ for the duration of the culture (Days 0-6). As with the fetal ovary cultures, etoposide was dissolved in DMSO, which was therefore also added to control medium, all media containing $0.1 \%$ DMSO. All treatments were $n=6$, with previously published work showing this to be sufficient group size [34].

\section{Histological follicle assessment}

At the end of culture, ovaries were placed in $10 \%$ buffered formalin (Sigma Aldrich) for $24 \mathrm{~h}$ at room temperature, paraffin wax-embedded, sectioned at $5 \mu \mathrm{m}$ 
and stained with haemotoxylin and eosin. Every sixth section was photomicrographed and follicle counts along with assessment of follicle stage and health was carried out, with the observer blind as to treatment. A follicle was included in analysis only where the analysed section contained an oocyte with a visible germinal vesicle. A follicle was considered to be at the PF stage if it contained only flattened pre-granulosa cells, at the transitional stage if it contained both flattened and cuboidal granulosa cells, or at the primary or secondary stage where there was one or two complete layer(s) of cuboidal granulosa cells respectively. Follicle health was recorded onto a separate sheet, with follicles only considered healthy if there was a round oocyte containing a central nucleus and evenly stained cytoplasm, and in the absence of pyknotic granulosa cells. Oocytes were considered unhealthy if they contained a shrunken and pyknotic nucleus or granulosa cells, identified by a dark eosin stain. The Abercrombie correction factor was applied to raw counts to estimate total follicle number per ovary [48].

\section{Immunohistochemistry}

Sycp3 immunohistochemistry: meiotic progression in mouse oocytes

Progression through meiotic prophase I was monitored by assessing SC assembly, using antibodies to Sycp3. E13.5 ovaries were cultured in the presence or absence of etoposide $\left(150 \mathrm{ng} \mathrm{m}^{-1}\right)$ for 2,4 or 6 days. Ovaries were fixed in $10 \%$ buffered formalin, sectioned, dewaxed, rehydrated and antigen retrieval carried out (0.01 M citrate buffer, $\mathrm{pH}$ 6). Endogenous peroxidase activity was blocked with $3 \%$ hydrogen peroxide $\left(\mathrm{H}_{2} \mathrm{O}_{2}\right.$; Sigma Aldrich) in methanol for 30 mins. Slides were washed ( $1 \mathrm{x}$ phosphate buffered saline [PBS], $0.1 \%$ Triton X-100, Sigma Aldrich) and then incubated for $1 \mathrm{~h}$ with $20 \%$ normal goat serum (1x PBS, 5 \% bovine serum albumin [BSA]) to block non-specific binding. Sections were incubated overnight at $4{ }^{\circ} \mathrm{C}$ with primary mouse anti-Sycp3 antibody (Abcam, 97672), diluted 1:200 in $20 \%$ goat serum ( $1 \mathrm{x}$ PBS, $5 \%$ BSA), washed (1x PBS, $0.1 \%$ Triton $\mathrm{X}-100)$ and then incubated for 60 mins with Alexa Fluor 568 secondary anti-mouse antibody (Invitrogen, A21124) diluted 1:200. For visualisation, slides were incubated in DAPI counterstain (Invitrogen, D3571) diluted 1:10000 for 20 mins, washed, mounted using Vectashield (Vector, H-1400) and coverslipped. Photomicrographs (Leica A6000 fluorescent microscope) were obtained for the largest cross section of each cultured ovary. For analysis, counts were made of all oocyte nuclei in leptotene, zygotene, pachytene or diplotene stage of meiotic prophase, with an average of 160 oocytes counted per ovary ( $n=961$ control oocytes, $n=994$ etoposide oocytes).

\section{Localisation of Topo Ila}

CD1 mouse ovaries were collected each day from E13.5 embryos through to P6 pups, along with ovaries collected from the fetal ovary culture (Days 1-12). Human ovarian tissue was obtained following elective termination of pregnancy, with informed written consent and approval from the SE Scotland Ethics Committee (reference number $06 / S 1102 / 4$ ). Immunohistochemistry was carried out as above with changes as detailed. Antibodies used were: primary - rabbit anti-Topo II $\alpha$ antibody (Abcam, ab52934), diluted 1:100; secondary - biotinylated goat anti rabbit antibody (Dako UK Ltd, Cambridgeshire, UK), diluted 1:200. For visualisation, slides were incubated 30 mins using $A B C$ kit (Vector labs, Peterborough, UK), washed and incubated in DakoCytomation EnVision + DualLink System, Peroxidase $(\mathrm{DAB}+)$ solution (Vector labs). Reaction was quenched in $\mathrm{H}_{2} \mathrm{O}$, slides washed, counterstained for $30 \mathrm{~s}$ in haematoxylin, dehydrated and mounted with DPX and glass coverslips.

\section{Statistical analysis}

Statistical analyses were conducted using Graphpad prism (GraphPad Software, Inc., La Jolla, CA, USA). Proportions of germ cells in different stages of meiosis were compared using chi squared analysis. For all other studies involving more than one dose group, data were analysed as follows. Data normality was assessed using Kolmogorov Smirnoff tests. Where data were normally distributed, one way ANOVA was used to detect statistically significant differences across treatments, followed by Bonferroni post-hoc test where ANOVA showed statistical significance. Where data were not normally distributed, Kruskal-Wallis non-parametric test was used, followed by Dunns post-hoc test where Kruskal-Wallis showed statistical significance. Unpaired two-tailed ttests were used when analyses compared only two groups. Raw data are provided in Additional file 2.

\section{Additional files}

Additional file 1: Images of embryonic ovaries in culture. (PDF 378 kb) Additional file 2: Full data set for Figures 2-7. (XLSX $35 \mathrm{~kb}$ )

\section{Abbreviations \\ E, embryonic day; P, postnatal day; PF, primordial follicle; SC, synaptonemal complex; Topo II, type II Topoisomerase}

\section{Acknowledgement \\ We thank Hazel Kinnell for assistance with the immunohistochemistry on human ovary sections.}

Funding

Work was supported by Medical Research Grant (MRC) grants G1002118 (NS, RAA) and G1100357 (RAA) and by MRC intramural programme grant to IRA with AS supported in part by a BBSRC-AstraZeneca CASE studentship. 


\section{Availability of data and materials}

Raw data are provided in Additional file 2.

\section{Authors' contributions}

AS participated in design of the study, was the lead in all experiments and drafted the manuscript with NS. ZCJ performed culture experiments. NP-G and RAA participated in design of the study and helped draft the manuscript. IRA participated in design of the study and in initial cultures and analysis of Sycp3 expression, and helped to draft the manuscript. NS designed and coordinated the study and drafted the manuscript with AS. All authors read and approved the final manuscript.

\section{Competing interests}

Nicola Powles-Glover is employed by AstraZeneca. The remaining authors declare that they have no competing interests.

\section{Consent for publication}

Not applicable.

\section{Ethics approval and consent to participate}

Human ovarian tissue was obtained following elective termination of pregnancy, with informed written consent and approval from the SE Scotland Ethics Committee (reference number 06/S1102/4). All experiments were approved by the University of Edinburgh's Local Ethical Review Committee and carried out in accordance with UK Home Office regulations under the ASPA 1986 act.

\section{Author details}

${ }^{1}$ Centre for Integrative Physiology, University of Edinburgh, Edinburgh EH8 9XD, UK. ${ }^{2}$ AstraZeneca, Alderley Park, Macclesfield SK10 4TG, UK. ${ }^{3}$ MRC Centre for Reproductive Health, University of Edinburgh, Edinburgh EH16 4TJ, UK. ${ }^{4}$ MRC Human Genetics Unit, MRC Institute of Genetics and Molecular Medicine, University of Edinburgh, Edinburgh EH4 2XU, UK. ${ }^{5}$ Present Address: Institute of Biodiversity, Animal Health and Comparative Medicine, University of Glasgow, Glasgow G61 1QH, UK.

\section{Received: 19 November 2015 Accepted: 5 July 2016}

Published online: 11 August 2016

\section{References}

1. Kluetz PG, Edelman MJ. Successful treatment of small cell lung cancer during pregnancy. Lung Cancer. 2008;61:129-30.

2. Aviles A, Neri N. Hematological malignancies and pregnancy: a final report of 84 children who received chemotherapy in utero. Clin Lymphoma. 2001; 2(3):173-7.

3. Vandenbroucke T, Verheecke M, Van Calsteren $K$, Han S, Claes L, Amant F. Fetal outcome after prenatal exposure to chemotherapy and mechanisms of teratogenicity compared to alcohol and smoking. Expert Opin Drug Saf. 2014;13(12):1653-65.

4. Meirow D, Schiff E. Appraisal of chemotherapy effects on reproductive outcome according to animal studies and clinical data. J Natl Cancer Inst Monogr. 2005;34:21-5.

5. Lambertini M, Peccatori FA, Azim HAJ. Targeted agents for cancer treatment during pregnancy. Cancer Treat Rev. 2015;41(4):301-9.

6. Cardonick $E$, lacobucci $A$. Use of chemotherapy during human pregnancy. Lancet Oncol. 2004;5(5):283-91.

7. Ring AE, Smith IE, Jones A, Shannon C, Galani E, Ellis PA. Chemotherapy for breast cancer during pregnancy: an 18-year experience from five London teaching hospitals. J Clin Oncol. 2005;23(18):4192-7.

8. Amant F, Vandenbroucke T, Verheecke M, Fumagalli M, Halaska MJ, Boere I, Han S, Gziri MM, Peccatori F, Rob L, et al. Pediatric Outcome after Maternal Cancer Diagnosed during Pregnancy. N Engl J Med. 2015. Epub ahead of print.

9. Zemlickis D, Lishner M, Degendorfer P, Panzerella T, Sutcliffe SB, Koren G. Fetal outcome after in utero exposure to cancer chemotherapy. Arch Intern Med. 1992;152(3):573-6.

10. Morgan S, Anderson RA, GGourley C, Wallace WH, Spears N. How do chematherapeutic agents damage the ovary? Hum Reprod. 2012;18(5): 525-35

11. De Vos M, Smitz J, Woodruff K. Fertility preservation in women with cancer. Lancet. 2014;384(9950):1302-10.
12. Royal College of Physicians TRCoR, Royal, Gynaecologists CoOa. The effects of cancer treatment on reproductive functions: guidance on management. In: Report of working party RCP RCR RCOG. London: RCP; 2007.

13. Comish PB, Drumond AL, Kinnell HL, Anderson RA, Matin A, Meistrich ML, et al. Fetal cyclophosphamide exposure induces testicular cancer and reduced spermatogenesis and ovarian follicle numbers in mice. PLoS One. 2014;9: e93311.

14. Barekati Z, Gourabi H, Valojerdi MR, Yazdi PE. Previous maternal chemotherapy by cyclophosphamide (Cp) causes numerical chromosome abnormalities in preimplantation mouse embryos. Reprod Toxicol. 2008;26:278-81.

15. Forabosco A, Sforza C. Establishment of ovarian reserve: a quantitative morphometric study of the developing human ovary. Fertil Steril. 2007; 88(3):675-83.

16. Schindler R, Nilsson EE, Skinner MK. Induction of ovarian primordial follicle assembly by connective tissue growth factor CTGF. PLoS One. 2010;5(9): e12979.

17. Han JY, Nava-Ocampo AA, Kim TJ, Shim JY, Park CT. Pregnancy outcome after prenatal exposure to bleomycin, etoposide and cisplatin for malignant ovarien germ cell tumors: report of 2 cases. Reprod Toxicol. 2005;19(4):557-67.

18. Siepermann M, Koscielniak E, Dantonello T, Klee D, Boos J, Krefeld B, et al. Oral low-dose chemotherapy: successful treatment of an alveolar rhabdomyosarcoma during pregnancy. Pediatr Blood Cancer. 2012;58(1):104-6.

19. Karimi Zarchi M, Behtash N, Modares Gilani M. Good pregnancy outcome after prenatal exposure to bleomycin, etoposide and cisplatin for ovarian immature teratoma: a case report and literature review. Arch Gynecol Obstet. 2008;277:75-8

20. Ghaemmaghami F, Hsanzadeh M. Good fetal outcome of pregnancies with gynecologic cancer conditions: cases and literature review. Int J Gynecol Cancer. 2006;16(Suppl1):225-30.

21. Ghaemmaghami F, Abbasi F, Abadi AG. A favorable maternal and neonatal outcome following chemotherapy with etoposide, bleomycin, and cisplatin for management of grade 3 immature teratoma of the ovary. J Gynecol Oncol. 2009;20:257-9.

22. Montecucco A, Biamonti G. Cellular response to etoposide treatement. Cancer Lett. 2007;252:9-18.

23. Roca J. Topoisomerase II: a fitted mechanism for the chromatin landscape. Nucleic Acids Res. 2009;37:721-30.

24. Nitiss JL. DNA topoisomerase $\|$ and its growing repertoire of biological functions. Nat Rev Cancer. 2009;9:327-37.

25. Chen GL, Yang L, Rowe TC, Halligan BD, Tewey KM, Liu LF. Non-intercalative antitumour drugs interfere with the breakage reunion reaction of mammalian DNA topoisomerase II. Biol Chem. 1984;259:13560-6.

26. Gupta RS, Bromke A, Bryant DW, Gupta RK, Sing B, McCalla DR. Etoposide (VP16) and teniposide (VM26): novel anticancer drugs, strongly mutagenic in mammalian but not prokaryotic test systems. Mutagenesis. 1987;2(3):179-86.

27. Fortune JM, Osheroff N. Topoisomerase II as a target for anticancer drugs: when enzymes stop being nice. Prog Nucleic Acid Res Mol Biol. 2000;64: 221-53.

28. Burden DA, Osheroff N. Mechanism of action of eukaryotic topoisomerase II and drugs targeted to the enzyme. Biochim Biophys Acta. 1998;1400(1-3): 139-54.

29. Zhang YL, Yu C, Ji SY, Li XM, Zhang YP, Zhang D, et al. TOP2B is essential for ovarian follicles that are hypersensitive to chemotherapeutic drugs. Mol Endocrinol. 2013;27(10):1678-91.

30. Russell LB, Hunsicker PR, Hack AM, Ashley T. Effect of the topoisomerase-II inhibitor etoposide on meiotic recombination in male mice. Mutat Res. 2000;464(2):201-12.

31. Li XM, Yu C, Wang ZW, Zhang YL, Liu XM, Zhou D, et al. DNA topoisomerase II is dispensable for oocyte meiotic resumption but is essential for meiotic chromosome condensation and separation in mice. Biol Reprod. 2013;89(5):118.

32. Marchetti F, Bishop JB, Lowe X, Generoso WM, Hozier J, Wyrobek AJ. Etoposide induces heritable chromosomal aberrations and aneuploidy during male meiosis in the mouse. Proc Natl Acad Sci U S A. 2001;98(7):3952-7.

33. Desmeules $P$, Devine PJ. Characterization of a rat in vitro ovarian culture system to study the ovarian toxicant 4-vinycyclohexene diepoxide. Toxicol Appl Pharmacol. 2006;184(2):107-15.

34. Morgan S, Lopes F, Gourley C, Anderson RA, Spears N. Cisplatin and doxorubicin induce distinct mechanisms of ovarial follicle loss; imatinib provides selective protection only against cisplatin. PLoS One. 2013;8(7):43-8. 
35. Dobson MJ, Pearlman RE, Karaiskakis A, Spyropoulos B, Moens PB. Synaptonemal complex proteins: occurrence, epitope mapping and chromosome disjunction. J Cell Sci. 1994;107(Pt 10):2749-60.

36. Lammers JHM, Offenberg HH, Van Alderen M, Vink ACG, Dietrich AJJ, Heyting C. The gene encoding a major component of the lateral elements of synaptonemal complexes of the rat is related to X-linked lymphocyte-regulated genes. Mol Cell Biol. 1994;14:1137-46.

37. Speed RM. Meiosis in the foetal mouse ovary. I. An analysis at the light microscope level using surface spreading. Chromosoma. 1982;85:427-37.

38. Hande KR, Wedlund PJ, Noone RM, Wilkinson GR, Greco FA, Wolff SN. Pharmacokinetics of high-dose etoposide (VP-16-213) administered to cancer patients. Cancer Res. 1984;44(1):379-82.

39. Moneypenny CG, Shao J, Song Y, Gallagher EP. MLL rearrangements are induced by low doses of etoposide in human hematopoietic stem cells. Carcinogenesis. 2006:27(4):874-81.

40. De Felici M, McLaren A. In vitro culture of mouse primordial germ cells. Exp Cell Res. 1983;144(2):417-27.

41. McLaren A, Buehr M. Development of mouse germ cells in cultures of fetal gonads. Cell Differ Dev. 1990;31:185-95.

42. Hartshorne GM, Barlow AL, Child TJ, Barlow DH, Hulten MA. Immunocytogenetic detection of normal and abnormal oocytes in human fetal ovarian tissue in culture. Hum Reprod. 1999:14(1):172-82.

43. Adams IR, McLaren A. Sexually dimorphic development of mouse primordia germ cells: switching from oogenesis to spermatogenesis. Development. 2002;129:1155-64.

44. Brieno-Enriquez MA, Robles P, Garcia-Cruz R, Roig I, Cabero L, Martinez F, et al. A new culture technique that allows in vitro meiotic prophase development of fetal human oocytes. Hum Reprod. 2010;25(1):74-84.

45. Zhang Z, Lian G, Zhang X, Zhang G, Chao H, Li L, et al. Growth of mouse oocytes to maturity from premeiotic germ cells in vitro. PLoS One. 2012; 7(7):e41771.

46. Jorgensen A, Nielsen JE, Perlman S, Lundvall L, Mitchell RT, Juul A, et al. Ex vivo culture of human fetal gonads: manipulation of meiosis signalling by retinoic acid treatment disrupts testis development. Hum Reprod. 2015; 30(10):2351-63.

47. Obata YM, Kono T, Hatada I. Maturation of mouse fetal germ cells in vitro. Nature. 2002:418:497-8.

48. Abercrombie M. Estimation of nuclear population from microtome sections. Anat Rec. 1946:94:239-47.

\section{Submit your next manuscript to BioMed Central and we will help you at every step:}

- We accept pre-submission inquiries

- Our selector tool helps you to find the most relevant journal

- We provide round the clock customer support

- Convenient online submission

- Thorough peer review

- Inclusion in PubMed and all major indexing services

- Maximum visibility for your research

Submit your manuscript at www.biomedcentral.com/submit

) Biomed Central 